\title{
Timing of invasive strategy in patients with non-ST-segment elevation acute coronary syndrome and effect on clinical outcomes
}

\author{
Vladan Vukcevic ${ }^{1,2}$, Goran Stankovic ${ }^{1,2}$ \\ ${ }^{1}$ Department of Cardiology, Clinical Center of Serbia, Belgrade, Serbia; ${ }^{2}$ Faculty of Medicine, University of Belgrade, Belgrade, Serbia \\ Correspondence to: Vladan Vukcevic, MD, PhD. Department of Cardiology, Clinical Center of Serbia, 26 Visegradska, 11000 Belgrade, Serbia. \\ Email: vladan.vukcevic@gmail.com. \\ Provenance: This is an invited Editorial commissioned by the Section Editor Hai-Long Dai (Department of Cardiology, Yan'an Affiliated Hospital of \\ Kunming Medical University, Kunming, China). \\ Comment on: Jobs A, Mehta SR, Montalescot G, et al. Optimal timing of an invasive strategy in patients with non-ST-elevation acute coronary \\ syndrome: a meta-analysis of randomised trials. Lancet 2017;390:737-46.
}

Submitted Sep 26, 2017. Accepted for publication Oct 01, 2017.

doi: $10.21037 /$ jtd.2017.10.21

View this article at: http://dx.doi.org/10.21037/jtd.2017.10.21

Acute coronary syndromes without persistent STsegment elevation [non-ST-segment elevation acute coronary syndrome (NSTE-ACS)] share similar pathophysiological mechanism with acute ST-segmentelevation myocardial infarction (STEMI), and rupture or erosion of atherosclerotic plaque may lead to the formation of either non-occlusive or occlusive thrombus $(1,2)$. Since the initial excitement we all felt when Andreas Gruentzig introduced the balloon angioplasty in the clinical practice, patients with acute coronary syndrome were always in the focus of interventional cardiologists. Primary percutaneous coronary intervention (PPCI) is recommended treatment strategy for STEMI patients, with a robust evidence for reduction in mortality. The best individual treatment strategy is more complex to determine in patients with NSTE-ACS, since ruptured plaque, with non-occlusive thrombus and patent coronary artery, might potentially progress to formation of occlusive thrombus and STEMI. In the last 15 years, with significant improvement in PCI device technology, introduction of newer generation drug eluting stents and new and more potent antiplatelet and anti-inflammatory drugs, a significant number of studies was conducted in NSTEACS to compare initially conservative versus routine invasive approach according to risk profile, as well as to determine the optimal timing for invasive approach (3-16). Recent European guidelines for NSTE-ACS recommend routine invasive strategy, with coronary angiography within 24-72 hours, for patients with intermediate and high-risk characteristics, since multiple randomized clinical trials (RCTs) have shown improved clinical outcomes compared to routine conservative strategy (1). However, the issue of optimal timing of early versus delayed invasive approach has not been settled due to conflicting results of contemporary RCTs $(3,7,10,14,15,17-21)$. Possible reasons for differential outcomes are related to heterogeneity in patient populations studied, timing of invasive intervention and concomitant medical therapy because sealing of ruptured plaque by coronary stent implantation could stabilize clinical situation and prevent further complications by preventing the extension of myocardial necrosis, while, on the other hand, early intervention and PCI of unstable plaque may result in higher rate of complications, with distal embolization and development of no-reflow phenomenon or total occlusion of previously patent coronary artery and therefore the higher risk of peri-procedural MI (8).

Multiple randomized studies and collaborative metaanalysis tried to strengthen and support data for initially invasive or initially conservative approach by increasing the total number of patients included $(8,12,13,22)$. Although none of these studies has proved that early invasive approach can decrease the occurrence of hard clinical endpoints (death or occurrence of new acute MI), most 
meta-analyses indicated the potential of earlier intervention to reduce recurrent ischemia, while mortality and new MI rates were not different as compared to cooling-off and delayed invasive strategy (8). Therefore, the decreases in total major adverse cardiovascular event (MACE), and especially decrease in number of ischemic events, lead to similar recommendations in European and American Guidelines $(3,7,8,10,12,15,23,24)$. Based primary on the Timing of Intervention in Acute Coronary Syndromes (TIMACS) trial, which showed lower combined rate of death, reinfarction or stroke in high-risk patients treated with early $v s$. delayed invasive strategy, current "European Guidelines for the management of acute coronary syndrome in patients presenting without persistent ST-segment elevation" suggest that coronary angiography should be performed within 24 hours in high-risk patients [Global Registry of Acute Coronary Events (GRACE) score >140] and within 72 hours in patients with intermediate risk (GRACE risk score between 109 and 139) (1).

Unfortunately, the great heterogeneity between studies made it difficult to create uniform recommendations for all NSTE-ACS presentations. First of all, majority of studies included unselected patients with acute coronary syndrome without ST-segment elevation, not only patients with clear criterion for NSTE acute MI (NSTEMI). Only LIPSIA-NSTEMI, RIDDLE-NSTEMI and Korean study included "homogeneous" NSTEMI patient population. Furthermore, the timing of early coronary angiography was different between the trials: some of them used STEMI-like approach and performed interventions very early (an average time from randomization to angiography was 2.4 hours in the ISAR-COOL, 1.1 hours in the LIPSIA-NSTEMI, and 1.4 hours in the RIDDLENSTEMI), while in the TIMACS that time was 14 hours and was 6 hours in the ELISA-3 $(8,12,24,25)$. Also, definition of peri-procedural MI differed significantly among studies: while majority of studies accepted solely rise of cardiac biomarkers, the RIDDLE-NSTEMI used clinical criteria for diagnosis, beside elevated cardiac biomarkers, new ST segment shift or occurrence of chest pain was needed $(8,9)$.

It seems that intra-study delay from admission to invasive intervention was a factor that played important role in the observed difference in study results (8). In two studies with the shortest time-delay to invasive treatment, the RIDDLENSTEMI and the ISAR COOL studies (time to invasive intervention was 1.4 and 2.4 hours) and in both studies significant decrease in composite adverse events of death and
MI was noted in early intervention groups (difference was mainly attributable to lower rates of new MI). Similarly, in both studies, frequency of MACE was similar in both early and delayed intervention groups after intervention. This may suggest that prolonging time from admission to diagnostic angiogram and possible intervention extends the period of the highest risk for the occurrence of adverse events, predominantly new MI. Similarly, in Danish NONSTEMI phase 1 study (NCT01638806), 5\% of patients randomized to conventional treatment developed STEMI while waiting for intervention. So, we can hypothesize that in selected high-risk group of NSTEMI patients, the longer waiting period for intervention, the larger probability for the occurrence of adverse ischemic events.

Recent meta-analysis of individual patient data from eight RCTs published in the Lancet provides important hypothesis generating data for identifying subgroups of patients who may particularly benefit from early invasive strategy (25). Jobs et al. have published a meta-analysis of RCT that compared early versus delayed invasive approach in NSTE-ACS, and reported at least 30 days mortality after in-hospital randomization (25). Individual data of 5,324 patients with a median follow-up of 180 days were available for analysis, which enabled them to analyze early and midterm clinical outcome in early versus delayed intervention groups, but also in several pre-specified subgroups. Importantly, none of eight individual studies showed a reduction in mortality and all were underpowered for this hard clinical outcome. Although authors of meta-analysis did not find the difference in mortality between overall population of early and delayed intervention groups [hazard ratio (HR), 0.81; 95\% confidence interval (CI), 0.64-1.03; $\mathrm{P}=0.0879$ ), they have found significant mortality reduction in a pre-specified high-risk subgroups: in diabetics, in elderly patients ( $\geq 75$ years of age), in patient with elevated cardiac biomarkers and in patients with high GRACE score (>140). Of interest, they also found in a post-hoc metaregression significant reduction of non-fatal MI.

Their findings undoubtedly strengthen guidelines recommendations to further explore the use of early invasive approach in identified high-risk subgroups of patients. But expanding a STEMI-like approach to NSTEMI patients will have significant impact on health resources and current STEMI networks. Are we ready for that change? Only a well-designed RCT, with standardized timing of early invasive strategy and clinically relevant definition of periprocedural MI and clinical outcome as a primary endpoint are necessary to recommend this approach in initially 
stabilized NSTE-ACS patients.

\section{Acknowledgements}

None.

\section{Footnote}

Conflicts of Interest: The authors have no conflicts of interest to declare.

\section{References}

1. Roffi M, Patrono C, Collet JP, et al. 2015 ESC Guidelines for the management of acute coronary syndromes in patients presenting without persistent ST-segment elevation: Task Force for the Management of Acute Coronary Syndromes in Patients Presenting without Persistent ST-Segment Elevation of the European Society of Cardiology (ESC). Eur Heart J 2016;37:267-315.

2. Amsterdam EA, Wenger NK, Brindis RG, et al. 2014 AHA/ACC Guideline for the Management of Patients with Non-ST-Elevation Acute Coronary Syndromes: a report of the American College of Cardiology/American Heart Association Task Force on Practice Guidelines. J Am Coll Cardiol 2014;64:e139-228.

3. Badings EA, The SH, Dambrink JH, et al. Early or late intervention in high-risk non-ST-elevation acute coronary syndromes: results of the ELISA-3 trial. EuroIntervention 2013;9:54-61.

4. de Winter RJ, Windhausen F, Cornel JH, et al. Early invasive versus selectively invasive management for acute coronary syndromes. N Engl J Med 2005;353:1095-104.

5. Fox KA, Poole-Wilson PA, Henderson RA, et al. Interventional versus conservative treatment for patients with unstable angina or non-ST-elevation myocardial infarction: the British Heart Foundation RITA 3 randomised trial. Randomized Intervention Trial of unstable Angina. Lancet 2002;360:743-51.

6. Mehta SR, Cannon CP, Fox KA, et al. Routine vs selective invasive strategies in patients with acute coronary syndromes: a collaborative meta-analysis of randomized trials. JAMA 2005;293:2908-17.

7. Mehta SR, Granger CB, Boden WE, et al. Early versus delayed invasive intervention in acute coronary syndromes. N Engl J Med 2009;360:2165-75.

8. Milasinovic D, Milosevic A, Marinkovic J, et al. Timing of invasive strategy in NSTE-ACS patients and effect on clinical outcomes: A systematic review and metaanalysis of randomized controlled trials. Atherosclerosis 2015;241:48-54.

9. Milosevic A, Vasiljevic-Pokrajcic Z, Milasinovic D, et al. Immediate Versus Delayed Invasive Intervention for NonSTEMI Patients: The RIDDLE-NSTEMI Study. JACC Cardiovasc Interv 2016;9:541-9.

10. Montalescot G, Cayla G, Collet JP, et al. Immediate vs delayed intervention for acute coronary syndromes: a randomized clinical trial. JAMA 2009;302:947-54.

11. Navarese EP, De Servi S, Gibson CM, et al. Early vs. delayed invasive strategy in patients with acute coronary syndromes without ST-segment elevation: a meta-analysis of randomized studies. QJM 2011;104:193-200.

12. Navarese EP, Gurbel PA, Andreotti F, et al. Optimal timing of coronary invasive strategy in non-ST-segment elevation acute coronary syndromes: a systematic review and meta-analysis. Ann Intern Med 2013;158:261-70.

13. O'Donoghue M, Boden WE, Braunwald E, et al. Early invasive vs conservative treatment strategies in women and men with unstable angina and non-ST-segment elevation myocardial infarction: a meta-analysis. JAMA 2008;300:71-80.

14. Tekin K, Cagliyan CE, Tanboga IH, et al. Influence of the Timing of Percutaneous Coronary Intervention on Clinical Outcomes in Non-ST-Elevation Myocardial Infarction. Korean Circ J 2013;43:725-30.

15. Thiele H, Rach J, Klein N, et al. Optimal timing of invasive angiography in stable non-ST-elevation myocardial infarction: the Leipzig Immediate versus early and late PercutaneouS coronary Intervention triAl in NSTEMI (LIPSIA-NSTEMI Trial). Eur Heart J 2012;33:2035-43.

16. Wallentin L, Lindhagen L, Arnstrom E, et al. Early invasive versus non-invasive treatment in patients with non-ST-elevation acute coronary syndrome (FRISC-II): 15 year follow-up of a prospective, randomised, multicentre study. Lancet 2016;388:1903-11.

17. Neumann FJ, Kastrati A, Pogatsa-Murray G, et al. Evaluation of prolonged antithrombotic pretreatment ("cooling-off" strategy) before intervention in patients with unstable coronary syndromes: a randomized controlled trial. JAMA 2003;290:1593-9.

18. Riezebos RK, Ronner E, Ter Bals E, et al. Immediate versus deferred coronary angioplasty in non-STsegment elevation acute coronary syndromes. Heart 2009;95:807-12. 
19. Sciahbasi A, Madonna M, De Vita M, et al. Comparison of immediate vs early invasive strategy in patients with first acute non-ST-elevation myocardial infarction. Clin Cardiol 2010;33:650-5.

20. van 't Hof AW, de Vries ST, Dambrink JH, et al. A comparison of two invasive strategies in patients with nonST elevation acute coronary syndromes: results of the Early or Late Intervention in unStable Angina (ELISA) pilot study. 2b/3a upstream therapy and acute coronary syndromes. Eur Heart J 2003;24:1401-5.

21. Zhang J, Qiao SB, Zhu J. Outcome of patients with non-ST segment elevation acute coronary syndrome undergoing early or delayed intervention. Zhonghua Xin Xue Guan Bing Za Zhi 2010;38:865-9.

22. Bavry AA, Kumbhani DJ, Rassi AN, et al. Benefit of early invasive therapy in acute coronary syndromes: a meta-

Cite this article as: Vukcevic V, Stankovic G. Timing of invasive strategy in patients with non-ST-segment elevation acute coronary syndrome and effect on clinical outcomes. J Thorac Dis 2017;9(11):4236-4239. doi: 10.21037/ jtd.2017.10.21 analysis of contemporary randomized clinical trials. J Am Coll Cardiol 2006;48:1319-25.

23. Katritsis DG, Siontis GC, Kastrati A, et al. Optimal timing of coronary angiography and potential intervention in non-ST-elevation acute coronary syndromes. Eur Heart J 2011;32:32-40.

24. Rajpurohit N, Garg N, Garg R, et al. Early versus delayed percutaneous coronary intervention for patients with nonST segment elevation acute coronary syndrome: a metaanalysis of randomized controlled clinical trials. Catheter Cardiovasc Interv 2013;81:223-31.

25. Jobs A, Mehta SR, Montalescot G, et al. Optimal timing of an invasive strategy in patients with non-ST-elevation acute coronary syndrome: a meta-analysis of randomised trials. Lancet 2017;390:737-46. 